\title{
Survival strategy of urology department during the COVID-19 era
}

\author{
Se Young Choi ${ }^{1}$ Tae-Hyoung Kim ${ }^{1}$
}

Received: 11 May 2020 / Accepted: 18 May 2020 / Published online: 29 May 2020

(c) Springer Nature B.V. 2020

Keywords COVID-19 $\cdot$ Urology $\cdot$ University hospital

\section{Editor,}

The outbreak of coronavirus disease 2019 (COVID-19) was first reported in Wuhan, China and rapid spread has changed the lifestyles of people all around the world [1]. On May 3rd 2020 , more than 3 million people confirmed and more than 200,000 people died all over the world [2].

The main symptoms are fever, myalgia, and cough, so relatively urologic fields may not have direct contact. However asymptomatic carriers could transmit COVID-19 to another person during the incubation period [3]. Any patients in urologic clinics can be a COVID-19 carrier. In addition, patients who had urologic problems are common in the elderly, who showed high mortality rates [4]. Therefore, prevention, control, and countermeasure against the COVID-19 are also important in the urology department.

Moreover, COVID-19 can become a hindrance to proper diagnoses and treatments for other patients without COVID19. The situation of COVID-19 limits health-service accessibility and can increase the mortality risks of other diseases. Transmissions into hospitals result in the loss of capability of medical treatment because of the forced isolation of the medical team and closure of wards or hospitals. In addition, there are lots of patients to care; therefore, the transmission can be more fatal. Our hospital in the middle of Seoul has about 800 beds and the number of employees is about 2000. The number of negative pressure isolation bed is seven in the ward, three in the intensive care unit, three in the emergency room, and two in the operation room. We also have two kinds of pre-isolation rooms until the results of COVID-19. One is five single-bed rooms using portable

Tae-Hyoung Kim

kthlmk@nate.com

1 Department of Urology, Chung-Ang University Hospital, Chung-Ang University College of Medicine, 102 Heukseok-ro, Dongjak-gu, Seoul 06973, Korea negative pressure devices for respiratory symptom patients. The other is two separate rooms with six beds for non-respiratory symptom patients before admissions or surgeries. We installed the screening center for COVID-19 in the outside of the hospital. We used the AllpexTM 2019-CoV Assay (Seegene, Seoul, Republic of Korea) using real-time quantitative reverse transcription-polymerase chain reaction before admission or surgery. Until now, there was no COVID-19 confirmation inside our hospital. We hope to share the principles in our hospital (Table 1). These are not intended for strict guidelines and are not supported by scientific evidence.

The advantage of the principles is to decrease the risk to inflow of COVID-19 inside the hospital without much delay. We could check the COVID-19 results of all patients who need admission or surgery within $12 \mathrm{~h}$. Patients who visit urology department can be divided into three groups, which are related to oncology, emergency, and non-oncology [5]. The waiting time for the COVID-19 results did not delay the schedule of patients with oncology or non-oncology, therefore we did not need to give up elective surgeries. In addition, patients who need admission or surgery could relieve anxiety about other patients with COVID-19 inside the hospital. Merely, the waiting time could cause problems for emergency patients who need emergent procedures. Delayed treatment about urologic emergencies may result in the mortality or severe functional impairment [6]. Testis torsion patients need detorsion surgery. Fournier's gangrene requires emergent surgical excision of necrotic tissues. Acute urinary retention, paraphimosis, and priapism also need proper procedures. Severe pains due to urinary stones should be reduced by proper painkillers. Trauma can make urologic emergencies, such as renal injury or penile amputation. In emergency cases without the results of COVID-19, we could use the negative isolation beds in emergency room or operation room. We prepared level $\mathrm{D}$ protection in the emergency room and N95 mask with protective glasses in the operation room. Because there is no significant treatment for the 
Table 1 Strategies to block the inflow into our hospital

\begin{tabular}{|c|c|c|}
\hline Supervision & Degree of recommendation & Comments \\
\hline Hospital & Compulsory & $\begin{array}{l}\text { All visitors take the temperature, fill in self-questionnaire about respiratory symptoms and leave } \\
\text { behind contact address }\end{array}$ \\
\hline Hospital & Compulsory & $\begin{array}{l}\text { All patients to undergo surgery or to be admitted to our hospital should take the COVID-19 screening } \\
\text { test }\end{array}$ \\
\hline Hospital & Compulsory & Install the screening center for suspected COVID-19 cases in the outside of the hospital \\
\hline Hospital & Compulsory & Prohibit visitors without wearing a mask \\
\hline Hospital & Compulsory & Prohibit visitors without a specific purpose (just visiting a sick person) \\
\hline Hospital & Compulsory & $\begin{array}{l}\text { Provide telecare to patients from the outbreak region or reserve outpatient appointment after isolation } \\
\text { of } 2 \text { weeks from the region }\end{array}$ \\
\hline Hospital & Compulsory & Distribute masks to employees \\
\hline Hospital & Compulsory & Use exclusive elevators for respiratory symptom patients \\
\hline Hospital & Compulsory & Arrange chairs into one direction in the employee cafeteria \\
\hline Hospital & Compulsory & Cancel all symposiums or conferences in our hospital \\
\hline Hospital & Compulsory & Prohibit overseas conference and trip (in unavoidable cases, self-isolation of 2 weeks after the return) \\
\hline Hospital & Compulsory & Report a family member's return from overseas to the infection control team \\
\hline Hospital & Compulsory & Prohibit non-employees enter to operation rooms \\
\hline Hospital & Recommendation & Avoid any meeting of more than 20 people in hospital \\
\hline Hospital & Recommendation & $\begin{array}{l}\text { In cases with repeat hospitalization such as chemotherapy, the first COVID-19 screening test is per- } \\
\text { mitted as long as no symptoms }\end{array}$ \\
\hline University & Compulsory & All polyclinics should take the temperature before the observation \\
\hline University & Recommendation & Provide video conference ID with a fee \\
\hline Department & Compulsory & Check outpatients' respiratory symptoms and visiting areas within 2 weeks before the out-clinic \\
\hline Department & Compulsory & All employees take the temperature twice in a day \\
\hline Department & Compulsory & $\begin{array}{l}\text { Any patients with new suspected symptom during admission should be isolated until negative } \\
\text { COVID-19 test }\end{array}$ \\
\hline Department & Compulsory & Divide a polyclinic group into minority \\
\hline Department & Compulsory & $\begin{array}{l}\text { Emergency operation before the results of COVID-19 should be held on the negative pressure isola- } \\
\text { tion room }\end{array}$ \\
\hline Personal & Recommendation & Abstain private meetings and keep social distances \\
\hline Personal & Recommendation & Wash hands to be clean frequently \\
\hline Personal & Recommendation & Video meeting for extramural people concerned \\
\hline
\end{tabular}

COVID-19 until now, the protection from the COVID-19 is the best way to save our patients.

The COVID-19 pandemic is changing medical situations. The first big changes embarrass us globally. However, the COVID-19 would be overcome by global cooperation. To make a safe urologic department in the hospital is to save our patients, family, and ourselves. These communications within urology will help to encourage in solving the COVID19 situations.

Funding This paper was supported by Bumsuk Academic Research Fund in 2019.

\section{Compliance with ethical standards}

Conflict of interest The authors declare no conflicts of interest.

\section{References}

1. Sohrabi C, Alsafi Z, O'Neill N et al (2020) World Health Organization declares global emergency: a review of the 2019 novel coronavirus (COVID-19). Int J Surg 76:71-76

2. (2020)Coronavirus Disease 2019 (COVID-19) situation report-104. World Health Organization

3. Yu P, Zhu J, Zhang Z, Han Y, Huang L (2020) A familial cluster of infection associated with the 2019 novel coronavirus indicating potential person-to-person transmission during the incubation period. J Infect Dis 221(11):1757-1761

4. Liu K, Chen Y, Lin R, Han K (2020) Clinical features of COVID19 in elderly patients: a comparison with young and middle-aged patients. J Infect 80(6):e14-e18

5. Naspro R, Da Pozzo LF (2020) Urology in the time of corona. Nat Rev Urol 17(5):251-253

6. Manjunath AS, Hofer MD (2018) Urologic emergencies. Med Clin N Am 102:373-385

Publisher's Note Springer Nature remains neutral with regard to jurisdictional claims in published maps and institutional affiliations. 